\title{
Modeling of the magnetizing phenomena of doubly fed induction generator using neuro-fuzzy algorithm considering non-linearity
}

Julia Tholath Jose, Adhir Baran Chattopadhyay

Departement of Electrical and Electronics, BITS Pilani Dubai Campus, Uni Emirat Arab

\begin{tabular}{l}
\hline Article Info \\
\hline Article history: \\
Received Feb 12, 2018 \\
Revised Jun 18, 2018 \\
Accepted Aug 2, 2018 \\
\hline
\end{tabular}

Keywords:

Discrete fourier transform Doubly fed induction generator Magnetizing characteristics Neuro-fuzzy algorithm Saturation

\begin{abstract}
Doubly fed Induction Generators (DFIGs) are quite common in wind energy conversion systems because of their variable speed nature and the lower rating of converters. Magnetic flux saturation in the DFIG significantly affect its behavior during transient conditions such as voltage sag, sudden change in input power and short circuit. The effect of including saturation in the DFIG modeling is significant in determining the transient performance of the generator after a disturbance. To include magnetic saturation in DFIG model, an accurate representation of the magnetization characteristics is inevitable. This paper presents a qualitative modeling for magnetization characteristics of doubly fed induction generator using neuro-fuzzy systems. Neuro-fuzzy systems with one hidden layer of Gaussian nodes are capable of approximating continuous functions with arbitrary precision. The results obtained are compared with magnetization characteristics obtained using discrete fourier transform, polynomial and exponential curve fitting. The error analysis is also done to show the effectiveness of the neuro fuzzy modeling of magnetizing characteristics. By neuro-fuzzy algorithm, fast learning convergence is observed and great performance in accuracy is achieved.
\end{abstract}

Copyright $(2019$ Institute of Advanced Engineering and Science. All rights reserved.

\section{Corresponding Author:}

Julia Tholath Jose,

Departement of Electrical and Electronics Engineering,

BITS Pilani Dubai Campus,

Dubai International Academic City, Dubai, Uni Emirat Arab.

Email: p20140003@dubai.bits-pilani.ac.in

\section{INTRODUCTION}

Wind energy is gaining importance in the present-day power scenario due to the rising concerns of the environmental issues along with the depletion of conventional sources and the increase in power demand. As reported by the world wind energy association (WWEA) that the total wind capacity in the world has attained $486,661 \mathrm{MW}$ by the end of 2016. This report also reveals that 54,846 MW were added in 2016. This indicates a growth rate of $11.8 \%$ in 2015 [1]. The main part of the wind energy conversion system is electrical generator. Nowadays wind turbines widely use doubly fed induction generator (DFIG), as it can operate for variable wind speeds. The stator of doubly fed induction generator (DFIG) is straightly connected to grid whereas the rotor is connected to the grid through a bidirectional voltage source converter. Accordingly, the control of the machine can be implemented with the converter of power rating of $25-30 \%$ of the rated power of the machine. This results in less cost, size and weight of converter and also less losses and increase in efficiency [2].

Wind energy conversion systems based on doubly fed induction generator are highly susceptible to grid disturbances such as voltage dips. Earlier DFIGs were disconnected from the gird during voltage dips. Due to the increased use of wind power, this disconnection of wind turbines may lead to loss of power and 
also to the system stability problems [3]. Besides, the sudden drop in grid voltage may cause over voltages and over currents in the rotor due to the magnetic coupling between stator and rotor. Due to these high currents, thermal breakdown of converter may occur. So according to new grid code requirements, all wind turbines must remain connected in the grid during short circuit also [4].

When the machine is subjected to several transients such as loading and short circuit faults, the ferromagnetic core of the machine saturates resulting in significant change in the electromagnetic parameters of the machine. Hence, actual machine responses can be different from the ones predicted by machine models that assumes linear magnetization characteristics. Therefore, the inductances that are usually treated constant in the conventional model are functionally dependent on machine currents. To have a machine model that resembles closely a real doubly fed induction generator, new terms representing the main flux saturation have to be included. Eventhough several works have done in the field of saturated induction motors, the effect of the magnetic saturation is usually neglected for DFIG. The saturation effect in the induction motor is analytically modeled in either the stator and rotor leakage flux paths [5]-[6] or in the main flux path [7]. On the other hand, experimental methods are utilized in [8] to incorporate the magnetic saturation in the main flux path, and in [9]-[10] to compensate for both the main and leakage flux paths. In [11] the main flux saturation is developed by replacing the unsaturated magnetizing inductance or reactance by its corresponding saturation function. Moreover, recent works are also available in [12]-[14] which considers the saturation based on analytical methods.

The effect of magnetic saturation in an electrical machine is realized by the mathematical formulation of the magnetization characteristics. Hence, an algorithm that can show functional relationship between current and flux will be useful for including the magnetization phenomena in electrical machine model [15]. Various methods have been presented by researchers to model the magnetizing characteristics from experimentally determined data points. It is found that functions such as exponential, rational and polynomial curve functions are used in literature to fit the magnetizing characteristic data points [16]-[24]. Soft computing techniques such as feed forward multilayer ANN networks are also developed to model saturation in electrical machines [25]-[27].

The objective of this paper is to develop a neuro-fuzzy model to represent the magnetization characteristics of the machine. As a universal approximator, neuro-fuzzy systems with Gaussian functions is used for the function approximation of magnetization characteristics. The mean square error is calculated to compare the results with the frequently used regression models such as polynomial, exponential and discrete Fourier transform (DFT). Neuro fuzzy algorithm is advantageous as its recursive nature of the computation results in enhanced function accuracy and also the parameters needed for approximation are only the centre and the width of the Gaussian membership function. Hence programmability for parametric learning is easy and straightforward. Even though, the polynomial models are advantangeously linear in parameters but it is limited in terms of generalization capabilities. As DFT is a sinusoidal approximation method, to increase the accuracy, order of cosine terms should be increased. This work can be considered as a preliminary step to a future implementation of neuro-fuzzy approximation in the modeling of DFIG for transient stability studies.

The section 2 explains the model of doubly fed induction generator and section 3 describes the nonlinearity of magnetizing characteristics and section 4 three existing models used to validate the proposed model and section 5 describes the general neuro-fuzzy structure and application of the neuro-fuzzy algorithm to develop the magnetization model of DFIG. The section 6 describes the numerical validation using the above algorithms. The section 7 includes the results and discussions.

\section{DOUBLY FED INDUCTION GENERATOR MODEL}

Doubly fed induction generator is essentially a wound rotor induction machine with its stator directly connected to the three-phase grid and rotor to the grid by two back to back converters namely the rotor-side converter and the grid-side converter [28]. Schematic diagram of DFIG as shows in Figure 1.

Int J Elec \& Comp Eng, Vol. 9, No. 1, February 2019: 23 - 33 


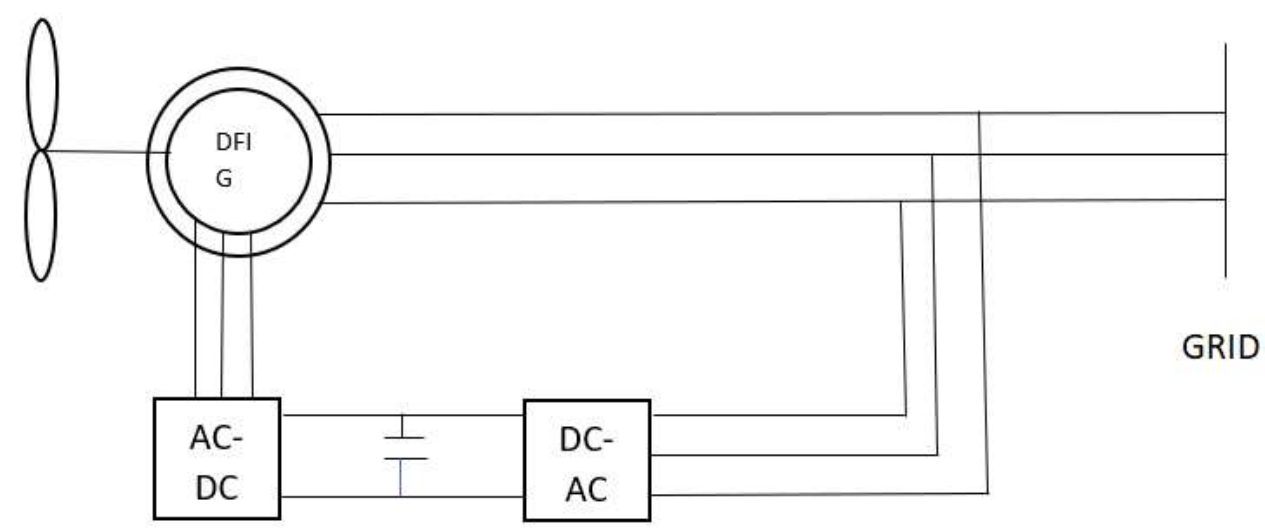

Figure 1. Schematic diagram of DFIG

The DFIG is modeled in synchronous $d q$ reference frame for the reason of simulation, analysis and control. Assuming the motor convention and taking into account of the flux linkage transients, the voltage and flux equations of DFIG are represented as [28].

$$
\begin{aligned}
& v_{s q}=R_{s} i_{s q}+\frac{d}{d t} \psi_{s q}+\omega_{s} \psi_{s d} \\
& v_{s d}=R_{s} i_{s d}+\frac{d}{d t} \psi_{s d}-\omega_{s} \psi_{s q} \\
& v_{r q}=R_{r} i_{r q}+\frac{d}{d t} \psi_{r q}+\left(\omega_{s}-\omega_{r}\right) \psi_{r d} \\
& v_{s q}=R_{s} i_{s q}+\frac{d}{d t} \psi_{s q}-\left(\omega_{s}-\omega_{r}\right) \psi_{s d}
\end{aligned}
$$

The stator and rotor fluxes are given by

$$
\begin{aligned}
& \psi_{s q}=L_{s} i_{s q}+L_{m} i_{r q} \\
& \psi_{s d}=L_{s} i_{s d}+L_{m} i_{r d} \\
& \psi_{r q}=L_{r} i_{r q}+L_{m} i_{s q} \\
& \psi_{r d}=L_{s} i_{r d}+L_{m} i_{s d}
\end{aligned}
$$

Where $L_{s}=L_{l s}+L_{m}$

$$
L_{r}=L_{l r}+L_{m}
$$

\section{NON-LINEARITY OF MAGNETIZATION CHARACTERISTICS}

The saturation of the ferromagnetic material used in the construction of electrical machines is responsible for the nonlinearity of magnetization characteristics. The conventional model of doubly fed induction machine shown in (1)-(2) employs constant value of magnetizing inductance as it assumes linear magnetization characteristics. As the flux is nonlinearly related to the magnetizing current, the conventional DFIG model formulated on the basis of linear magnetization characteristics fails to obtain precise results and causes performance predictions nearly inaccuratein many instances. Hence, more precise study of magnetization characteristics is necessarily needed to include the effect of magnetic saturation in the machine modeling [29]. Figure 2 shows the non-linear relationship between the magnetizing current and the opencircuit voltage. The main flux which is a function of magnetizing current can be expressed as

$$
L_{m}=\frac{\psi_{m}\left(i_{m}\right)}{i_{m}}
$$

As far as steady state is considered, the saturated magnetizing inductance is proportional to the chord slope of the saturation characteristic. 
In transient analysis of DFIG the incremental inductances are also required.

$$
\begin{aligned}
\frac{d}{d t} \psi_{m} & =\frac{d \psi_{m}}{d i_{m}} \frac{d i_{m}}{d t} \\
\frac{d}{d t} \psi_{m} & =L_{m t} \frac{d i_{m}}{d t}
\end{aligned}
$$

The transient magnetising inductance $L_{m t}$ is proportional to the tangential slope of the magnetization characteristic. The inductance $L_{m}$ and $L_{m}$ varies with the magnetizing current and appropriate method to identify them is to express the interpolating curve of the magnetization characteristic as non-linear function.

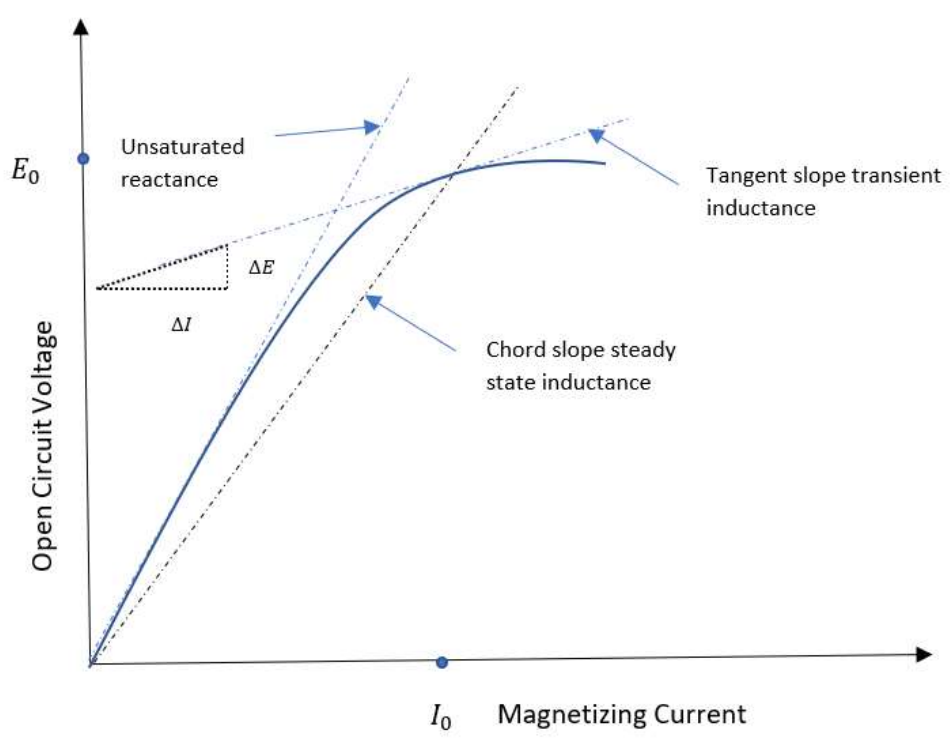

Figure 2. Magnetization characteristic

The dominance of magnetizing current depends on the load power factor. Hence, whenever magnetizing component of current is more, the core can have a tendency to saturate and the flux is no longer linearly proportional to magnetizing current. Then the degree of non-linearity of the magnetization characteristics has to be tracked. Under such condition, prediction about the success of operation is not possible without using numerical methods. Here lies the role of neuro-fuzzy method. Neurofuzzy system with back-propagation learning algorithms have the ability to learn a continuous nonlinear function from input and output data samples and effective in identifying nonlinear dynamic systems with unknown characteristics.

Accounting for magnetizing flux saturation, voltage equations of DFIG can be rewritten as [29].

$$
\begin{aligned}
& v_{s q}=R_{s} i_{s q}+L_{l s} \frac{d}{d t} i_{s q}+L_{m d} \frac{d}{d t} i_{m q}+\omega_{s}\left(L_{l s} i_{s d}+L_{m s} i_{m d}\right) \\
& v_{s d}=R_{s} i_{s d}+L_{l s} \frac{d}{d t} i_{s d}+L_{m d} \frac{d}{d t} i_{m d}+\omega_{s}\left(L_{l s} i_{s d}+L_{m s} i_{m q}\right) \\
& v_{r q}=R_{r} i_{r q}+L_{l r} \frac{d}{d t} i_{r q}+L_{m d} \frac{d}{d t} i_{m q}+\left(\omega_{s}-\omega_{r}\right)\left(L_{l s} i_{s d}+L_{m s} i_{m d}\right) \\
& v_{r d}=R_{r} i_{r d}+L_{l r} \frac{d}{d t} i_{r d}+L_{m d} \frac{d}{d t} i_{m d}-\left(\omega_{s}-\omega_{r}\right)\left(L_{l r} i_{r q}+L_{m s} i_{m q}\right)
\end{aligned}
$$

\section{DIFFERENT METHODS TO FIT MAGANETIZATION CHARACTERISTICS}

To fit a given set of data points, different mathematical techniques are available in literature. Here, we propose neuro fuzzy algorithm for modeling the magnetization characteristics. The results obtained from neuro fuzzy method have been validated with those obtained by discrete Fourier transform, polynomial and exponential curve fitting methods. 


\subsection{Discrete Fourier transform method}

Discrete Fourier transformation estimation can be used for $\mathrm{n}$ measured data points $\boldsymbol{\psi}_{\boldsymbol{m}} \& \boldsymbol{I}_{\boldsymbol{m}}$ to represent the magnetizing flux in sinusoidal format. The DFT of the magnetizing flux can be expressed as [30].

$$
\psi\left(I_{m}\right)=a_{0}+\sum_{j=1}^{k} a_{j} \cos \left(\omega_{j} I_{m}\right)
$$

where the coefficients are defined as

$$
\begin{aligned}
a_{0}= & \frac{1}{I_{\max }} \int_{0}^{I_{\max }} \psi(i) d i \\
= & \frac{1}{I_{\max }} \sum_{k=2}^{n}\left[\psi_{k}\left(I_{k}-I_{k-1}\right)-\frac{1}{2} \gamma_{k}\left(I_{k}-I_{k-1}\right)^{2}\right] \\
& \text { and } \\
& a_{j}=\frac{2}{I_{\max }} \int_{0}^{I_{\max }} \psi(i) \cos \left(\omega_{j} i\right) d i \\
= & \frac{1}{I_{\max }} \sum_{k=2}^{n}\left[\frac{\gamma_{k}}{\omega_{j}} \cdot \sin \left(\omega_{j} I_{k-1}\right) \cdot\left(I_{k}-I_{k-1}\right)+\frac{\gamma_{k}}{\omega_{j}^{2}}\left(\cos \left(\omega_{j} I_{k}\right)-\cos \left(\omega_{j} I_{k-1}\right)\right)+\right. \\
& \left.\frac{\psi_{k}}{\omega_{j}}\left(\sin \left(\omega_{j} I_{k}\right)-\sin \left(\omega_{j} I_{k-1}\right)\right)\right]
\end{aligned}
$$

where $\gamma_{k}, \omega_{j}$ and $I_{\max }$ are defined as

$$
\begin{gathered}
I_{\max }=I_{m n} \\
\omega_{j}=\frac{j \pi}{I_{\max }} \\
\gamma_{k}=\frac{\psi_{k}-\psi_{k-1}}{I_{k}-I_{k-1}}
\end{gathered}
$$

The number of cosine terms defines the order of the DFT function. For obtaining more precise results, the order of DFT should be increased.

\subsection{Polynomial curve fitting method}

Polynomial regression is one of the most widely used curve fitting method. The function representing the magnetization data is expressed in the form of a polynomial of order $\mathrm{j}$

$$
\psi\left(I_{m}\right)=a_{0}+a_{1} I_{m}+a_{2} I_{m}^{2}+\cdots+a_{j} I_{m}^{j}=a_{0}+\sum_{k=1}^{j} a_{k} I_{m}^{k}
$$

The coefficients that best fits the curve to the data points is obtained by error-least squares approach. The general expression for error using least squares approach is given by

$$
\text { Error }=\sum_{i=1}^{n}\left(\psi_{i}-\left(a_{0}+\sum_{k=1}^{j} a_{k} I_{m}^{k}\right)\right)^{2}
$$

The coefficients of the best fit curve are the one that minimizes the error function.

\subsection{Exponential curve fitting method}

The most widely accepted curve fitting function is of the form given by

$$
\psi\left(I_{m}\right)=\sum_{i=1}^{m} a_{i} e^{b_{i} I_{m}}
$$

The error function is given by

$$
\varepsilon=\sum_{j=1}^{n}\left(\psi\left(I_{m j}\right)-\psi_{j}\right)^{2}
$$


By the method of least square errors, the best fit coefficients can be obtained by minimizing the errors

$$
\begin{aligned}
& \frac{\partial \varepsilon}{\partial a_{1}}=\frac{\partial \varepsilon}{\partial a_{2}}=\cdots \frac{\partial \varepsilon}{\partial a_{n}}=0 \\
& \frac{\partial \varepsilon}{\partial b_{1}}=\frac{\partial \varepsilon}{\partial b_{2}}=\cdots \frac{\partial \varepsilon}{\partial b_{n}}=0
\end{aligned}
$$

\section{NEURO-FUZZY ALGORITHM}

Neural networks and fuzzy logic are two promising modern technologies. Neural networks are often regarded as "black box" approach since we cannot conceptually understand the pattern learned by the neural networks. Unlike neural networks, fuzzy system uses comprehendible linguistic terms and if-then rules [31].

The combination of neural networks and fuzzy logic led to the formation of neuro fuzzy system. A neuro-fuzzy system describes a fuzzy rule-based model using NN-like structure [32]. A collection of input output data is taken and a learning method comparable to the neural networks is employed to train and adjust the parameters of membership functions. A simple structure of ANFIS is presented in Figure 3 [33].

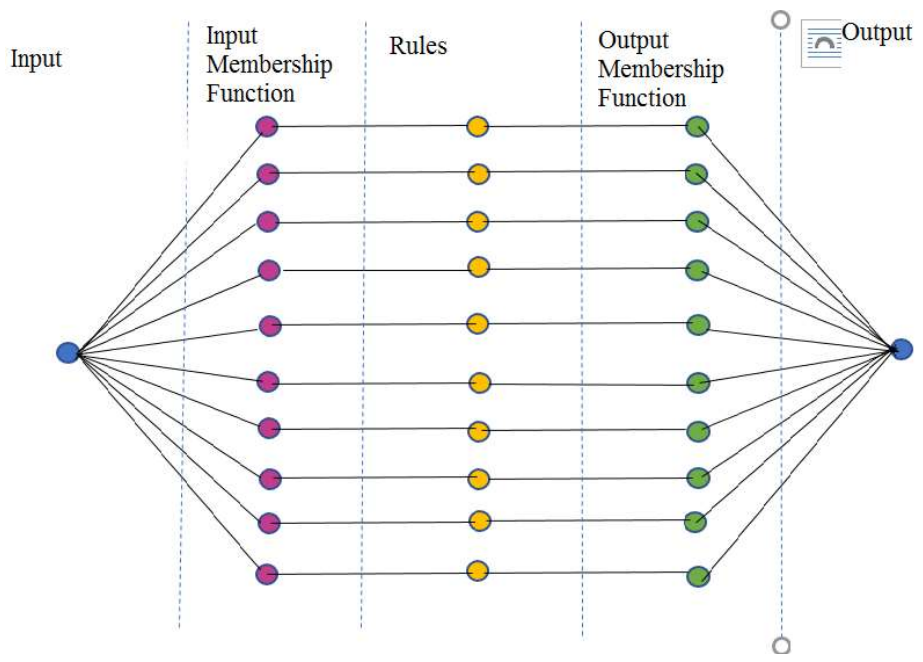

Figure 3. Structure of neuro-fuzzy system

Nonlinear curve fitting with neuro-fuzzy algorithm can be used to obtain the relation between magnetizing current and flux linkages with precision. The block diagram of the method is shown in Figure 4. The error is the difference between the flux linkages obtained from the experiment and the interpolated ones

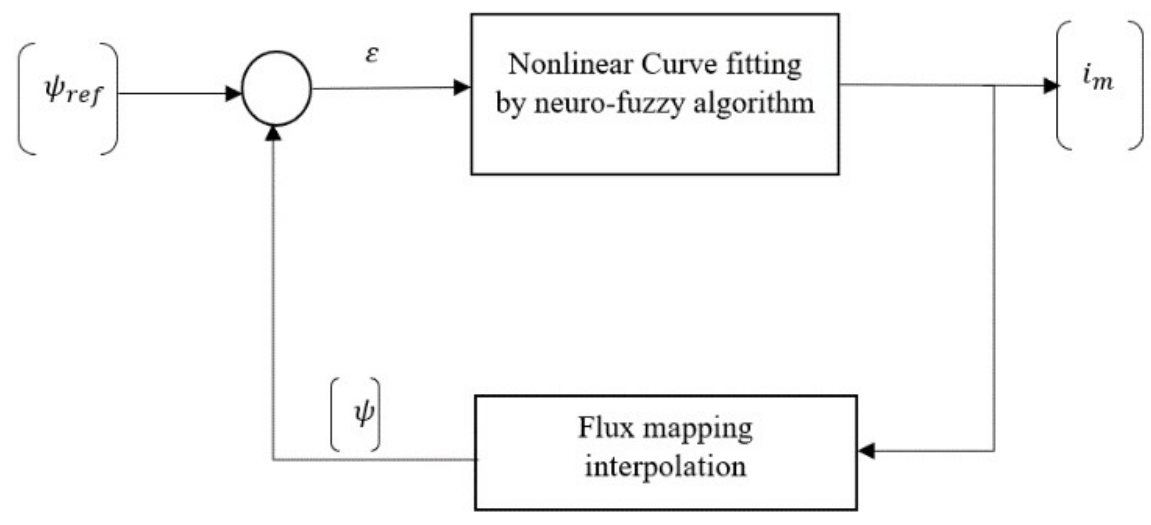

Figure 4. Block diagram to obtain flux-current relation 


\subsection{Neuro-fuzzy algorithm to fit magnetization characteristics}

A neuro fuzzy model to fit the magnetization characteristics data points of DFIG is demonstrated in this section. The neuro-fuzzy system used here is a first order Sugeno System with single input and three guassian distribution membership functions. Three if-then rules are used. The back-propagation algorithm is used to train this network. The training is performed by taking magnetizing current as the input and open circuit voltage corresponding to the magnetizing flux as the output. The linear membership functions are chosen for output.

The magnetizing current is the input which is represented by gaussian membership function. The linguistic variables for the fuzzy partitions of the magnetizing current are small, medium and large. The input magnetizing current is fuzzified using gaussian membership function is represented as [32].

$$
\mu_{A}(x)=\exp \left[-\left(\frac{x-m_{i}}{\sigma_{i}}\right)^{2}\right]
$$

where $\mathrm{x}$ is magnetizing current and $\mathrm{i}$ stands for linguistic variables. The ancedent parameters are centers $m_{s}, m_{m}, m_{l}$ and variances $\sigma_{s}, \sigma_{m}, \sigma_{l}$ of small, medium and large input membership functions.

The back-propagation algorithm used to train neuro fuzzy model consists of two passes, forward pass and backward pass. In the forward pass, for a given input the actual output of the system is computed using following equation [36].

$$
y_{k}=\sum_{i=1}^{M} v_{i}(k) c_{i}
$$

where

$$
v_{i}(k)=\frac{\exp \left[-\left(\frac{x-m_{i}}{\sigma_{i}}\right)^{2}\right.}{\sum_{i=1}^{m} \exp \left[-\left(\frac{x-m_{i}}{\sigma_{i}}\right)^{2}\right.}
$$

which represents the normalized firing strength of the rules and $c_{i}$ is the consequent parameter. In the forward pass, the ancedent parameters and the consequents that corresponds to the weights in the neural network are fixed. While during the backward pass, the error signal due to the difference of the real and the desired output of the model is propagated in backward direction and the ancedent and consequent parameters are updated by employing the gradient search algorithm. The error function at the kth iteration is denoted as [36].

$$
J(k)=\frac{1}{2}\left(y_{i}-\hat{y}_{i}\right)^{2}
$$

The error correction rules for $c_{i}, \sigma_{i}, m_{i}$ are given by

$$
\begin{aligned}
& c_{i}(k)=c_{i}(\mathrm{k}-1)-\left.\eta_{1} \frac{\partial J(k)}{\partial c_{i}}\right|_{c_{i}=c_{i(k-1)}} \\
& \sigma_{i}(k)=\sigma_{i}(\mathrm{k}-1)-\left.\eta_{2} \frac{\partial J(k)}{\partial \sigma_{i}}\right|_{\sigma_{i}=\sigma_{i(k-1)}} \\
& m_{i}(k)=m_{i}(\mathrm{k}-1)-\left.\eta_{1} \frac{\partial J(k)}{\partial m_{i}}\right|_{m_{i}=m_{i(k-1)}}
\end{aligned}
$$

where $\eta_{1}, \eta_{2}, \eta_{3}$ are the learning rate parameters.

$$
\begin{aligned}
& \frac{\partial J(k)}{\partial c_{i}}=\frac{\partial J(k)}{\partial e(k)} \frac{\partial e(k)}{\partial c_{i}}=-2 e(k) v_{i}(k) \\
& \frac{\partial J(k)}{\partial \sigma_{i}}=\frac{\partial J(k)}{\partial e(k)} \frac{\partial e(k)}{\partial v_{i}(k)} \frac{\partial v_{i}(k)}{\partial \sigma_{i}}=-2 e(k) v_{i}(k)\left[c_{i}-\sum_{l=1}^{M} v_{l}(k) c_{l}\right]\left[\frac{x(k)-m_{i}}{\sigma_{i}^{2}}\right] \\
& \frac{\partial J(k)}{\partial \sigma_{i}}=\frac{\partial J(k)}{\partial e(k)} \frac{\partial e(k)}{\partial v_{i}(k)} \frac{\partial v_{i}(k)}{\partial m_{i}}=-2 e(k) v_{i}(k)\left[c_{i}-\sum_{l=1}^{M} v_{l}(k) c_{l}\right]\left[\frac{\left(x(k)-m_{i}\right)^{2}}{\sigma_{i}^{3}}\right]
\end{aligned}
$$

The Batch Mode Backpropagation Algorithm applied to Takagi Sugeno Kang (TSK) models with Gaussian Membership Functions is as follows [36]. 
Step1: Set $c_{i}(0), m_{i}(0)$ and $\sigma_{i}(0)$ to small random numbers and set $\mathrm{n}=1$.

Step2: Compute $v_{i}(\mathrm{k})$ using equation for $\mathrm{k}=1,2, \ldots \ldots \ldots, \mathrm{N}$, where $m_{i}$ and $\sigma_{i}$ are replaced by $m_{i}(n-1)$ and $\sigma_{i}(n-1)$ respectively; Compute $\hat{y}(k)$ using equation for $\mathrm{k}=1,2, \ldots \ldots, \mathrm{N}$ where $c_{i}$ is replaced by $c_{i}(\mathrm{n}-1)$

Step3: From error signal $\mathrm{e}(\mathrm{k})=\mathrm{y}(\mathrm{k})-\hat{y}(k)$ for $\mathrm{k}=1,2 \ldots \ldots, \mathrm{N}$; update $c_{i}, m_{i}$ and $\sigma_{i}$ using equations respectively;

Step4: If some stopping criterion is satisfied, stop, otherwise set $n=n+1$ and go to step 2 .

\section{NUMERICAL VALIDATION}

The ratings of doubly fed induction generator considered in this paper is shown in appendix [34]. The open circuit voltage and magnetizing current needed for neuro fuzzy modeling of the magnetization characteristics of doubly fed induction generator is taken from [34]. The method to obtain the magnetization characteristics is by performing the open circuit test at synchronous speed. A three-phase controllable amplitude power source at the rated frequency has to be applied to the synchronously driven doubly fed induction generator. Vary the applied voltage to measure the terminal current. As the DFIG is operating at synchronous speed, the rotor current is zero and the magnetizing current is the terminal current itself [34].

The main flux saturation characteristics approximated using neuro-fuzzy model is shown along with data, DFT, polynomial and exponential in Figure 5. The parameters of neuro fuzzy system obtained are mentioned in Table 1. The training is performed using back propagation algorithm. Figure 6 shows the input membership functions of neuro fuzzy system after training process. To validate the accuracy of the neuro fuzzy method, the discrete, polynomial and exponential curve fitting method are also applied to magnetization data points. The calculated results are found to be matching with the measured ones. The accuracy of the proposed model is assessed by calculating mean square error. The mean square error can be determined by the given expression.

$$
M S E=\sum_{i=1}^{n} \frac{\left[X\left(I_{m i}\right)-X_{i}\right]^{2}}{n}
$$

where $X\left(I_{m i}\right)$ are the calculated values by the saturated levels at different magnetizing currents, $I_{m 1}, I_{m 2}, I_{m 3}, \ldots \ldots I_{m n}$, whereas $X_{1}, X_{2 \ldots \ldots \ldots . . .} X_{n}$ are the measured data points at these magnetizing currents. The results shown in Table 2 illustrate the effectiveness of neuro fuzzy method in fitting the magnetization characteristics of doubly fed induction generator. Figure 7 shows the mean square error obtained using neuro fuzzy method while training at each epoch. The number of training epochs is set to 50 with an error tolerance of .0005 .

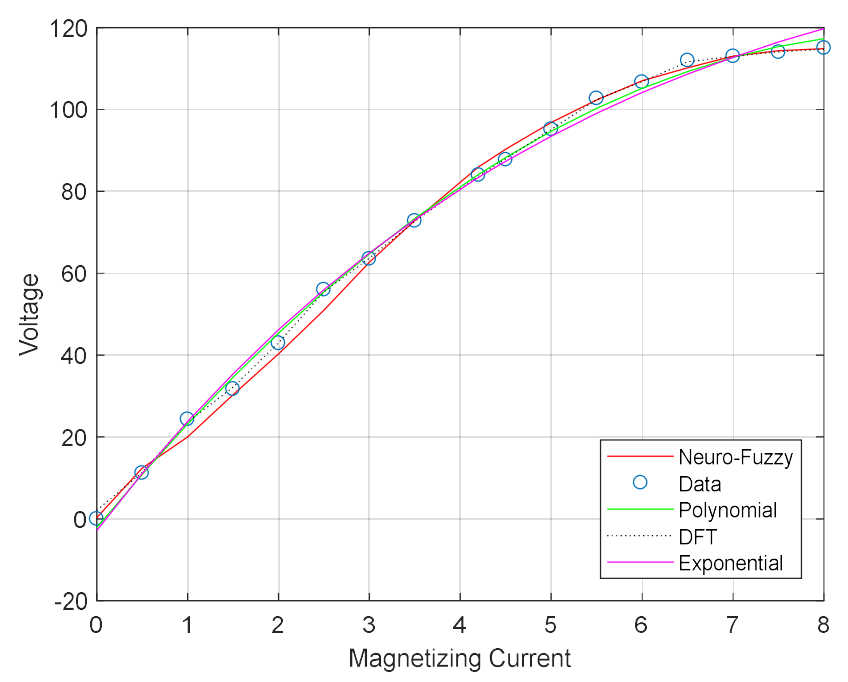

Figure 5. Calculated main flux saturation characteristics of the DFIG using different curve fitting method along with data 


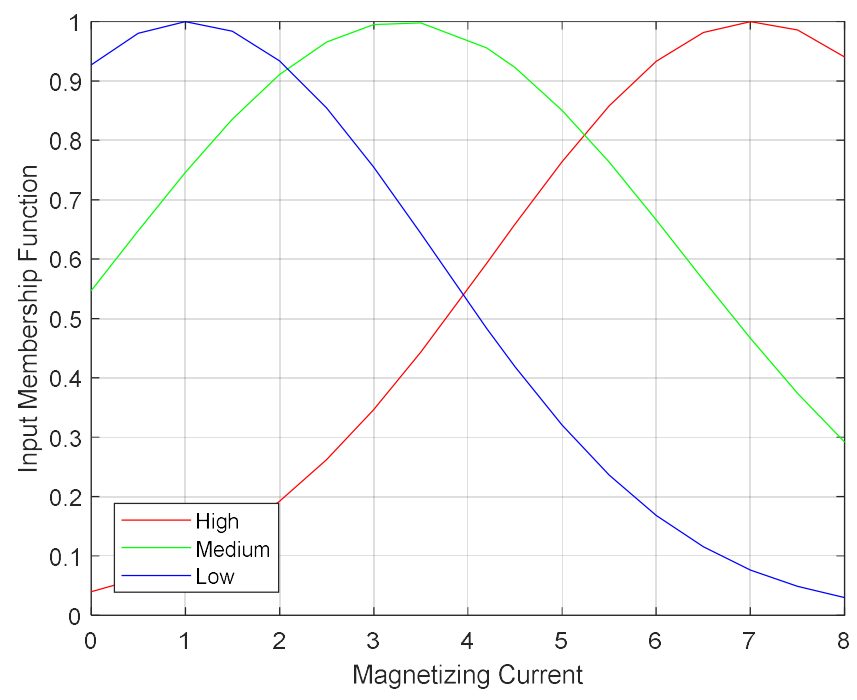

Figure 6. Input membership functions

Table 1. Parameters of the Neuro-fuzzy System

\begin{tabular}{cccc}
\hline & $\begin{array}{c}\text { Input Membership Function Parameters } \\
\text { Centre } m\end{array}$ & $\begin{array}{c}\text { Output Membership Function Parameter } \\
\text { Spread } \boldsymbol{\sigma}\end{array}$ & $\begin{array}{c}\text { Polynomial Constant } \\
\text { MF1 }\end{array}$ \\
MF2 & 2.1184 & 4.6507 & -1.3506 \\
MF3 & 4.6874 & 3.5622 & 0.6567 \\
\hline
\end{tabular}

Table 2. Mean Square Error of Different Methods

\begin{tabular}{ccc}
\hline Curve Fitting Method & Mean Square Error (MSE) & Maximum Error \\
\hline Neuro Fuzzy & 0.0005 & 0.0402 \\
DFT & 0.0088 & 0.0593 \\
Polynomial & 0.4452 & 0.9304 \\
Exponential & 0.4444 & 0.9101 \\
\hline
\end{tabular}

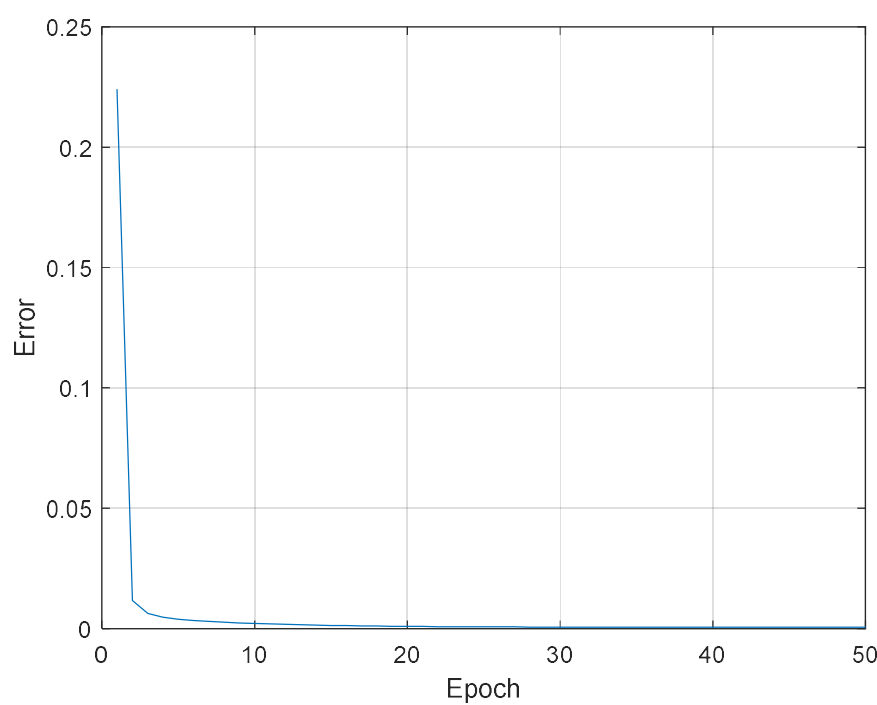

Figure 7. Training error using Neuro-fuzzy system 


\section{CONCLUSION}

Neuro Fuzzy System for modeling the magnetization characteristics of doubly fed induction generator has been developed in this paper. The propriety of using this model in estimating the magnetization characteristics of doubly fed induction generator has been investigated. Using predetermined magnetizing flux-current data sets, a neuro-fuzzy system can tune the parameters of membership function by using back propagation algorithm. The non-linearity of the magnetization characteristics is effectively plotted by this method. The mean square error has been calculated to measure the accuracy of the proposed method. Results obtained are compared with the discrete Fourier transform, polynomial and exponential regression methods. This shows the effectiveness of the proposed method in the modeling of magnetizing characteristics. The neurofuzzy model is also easier to implement as it needs to tune only parameters of input and output membership function.

It is concluded that neuro-fuzzy model developed can be used for magnetizing modeling of DFIG for its accuracy and reliability. Therefore, as the next step of the research, the magnetization model developed can be included in the state space model of DFIG. This will lead to a comprehensive and precise model which can be used for the performance analysis of doubly fed induction generator. In this sense, this work can be seen as a study previous to a future implementation of neuro-fuzzy approximation in the modeling of DFIG for steady state and transient stability studies.

\section{REFERENCES}

[1] www.wwindea.org/information-2/information by World Wind Energy Association (WWEA), June 2017.

[2] Muller.S, M. Deicke, and Rik W. De Doncker, "Doubly Fed Induction Generator Systems for Wind Turbines," IEEE Ind. Appl. Mag., Vol.8, no. 3, 26-33, 2002.

[3] Sarwar Kaloi, Ghulam, Jie Wang, and Mazhar H. Baloch, "Study of stabilty Analysis of a Grid Connected Doubly Fed Induction Generator Based on Wind Energy Application," Indonesian Journal of Electrical Engineering and Computer Science 3, no. 2, 305-313, 2016.

[4] Kong, Xiangping, Zhe Zhang, Xianggen Yin, and Zhenxing Li. "Study on Fault Current of DFIG during Slight Fault Condition," Indonesian Journal of Electrical Engineering and Computer Science 11, no. 4, 2221-2230, 2013.

[5] T. A. Lipo and A. Consoli, "Modeling and Simulation of Induction Motors with Saturable Leakage Reactances," IEEE Trans. Ind. Appl.,vol. IA-20, no. 1, pp. 180-189, Jan. 1984.

[6] P. Vas, "Generalized Analysis of Saturated AC Machines,” Elect. Eng., vol. 64, no. 1, pp. 57-62, Jan. 1981.

[7] Y. Xu and D. C. Aliprantis, "Experimental Parameterization Procedure for a Wound-Rotor Induction Generator," in Proc. IEEE Power Energy Conf. Illinois (PECI), Champaign, IL, USA, pp. 95-100, Feb. 2013.

[8] H. M. Jabr and N. C. Kar, "Starting Performance of Saturated Induction Motors," in Proc. IEEE Power Eng. Soc. Gen. Meeting,pp. 1-7, Jun. 2007.

[9] M. H. Jabr and N. C. Kar, "Leakage Flux Saturation Effects on the Transient Performance of Wound-Rotor Induction Motors," Electr. Power Syst. Res., vol. 78, no. 7, pp. 1280-1289, Jul. 2008.

[10] J. Pedra, I. Candela, and A. Barrera, "Saturation Model for Squirrel Cage Induction Motors," Electr. Power Syst. Res., vol. 79, no. 7, pp. 1054-1061, Jul. 2009.

[11] A Jabr, Hany M., and Narayan C. Kar. "Effects Of Main and Leakage Flux Saturation on the Transient Performances of Doubly-Fed Wind Driven Induction Generator," Electr. Power Syst. Research, Vol.77, 1019-1027, 2007.

[12] Masadeh, Mohammad A., K. S. Amitkumar, and Pragasen Pillay. "Power Electronic Converter-Based Induction Motor Emulator Including Main and Leakage Flux Saturation," IEEE Transactions on Transportation Electrification, 2018

[13] Alonge, Francesco, Maurizio Cirrincione, Marcello Pucci, and Antonino Sferlazza. "A Nonlinear Observer for Rotor Flux Estimation of Induction Motor Considering the Estimated Magnetization Characteristic." IEEE Transactions on Industry Applications 53, no. 6, 5952-5965, 2017.

[14] Accetta, Angelo, Francesco Alonge, Maurizio Cirrincione, Marcello Pucci, and Antonino Sferlazza. "Feedback Linearizing Control of Induction Motor Considering Magnetic Saturation Effects," IEEE Transactions on Industry Applications 52, no. 6, 4843-4854, 2016.

[15] Silva, M., N. Hummon, and L. Zaffanella. "Piecewise Fitting Function for Magnetisation Characteristics," Electrical Engineering Department, University of Khartoum, 1985.

[16] J. Rivas; J. Zamarro; E. Martin; C. "Pereira.Simple Approximation for Magnetization Curves and Hysteresis Loops," IEEE Transactions on Magnetics, Vol. 17,1498-1502, 1981.

[17] L.Lupsa-Tataru. "A Flux Based Expression Of Induction Machine By Magnetizing Inductance," IEEE Trans. Energy Convers. vol.25, 268-270, 2010.

[18] Y. Xu; D. C. "Aliprantis. Wound-rotor Induction Machine Model with Saturation and High-Frequency Effects," In Proceedings of the IEEE International Conference on Electrical Machines (ICEM), Berlin, Germany 2-5 Sept. 2014.

[19] Lu, Kaiyuan, and Ewen Ritchie. "Torque Analysis with Saturation Effects for Non-Salient Single-Phase PermanentMagnet Machines," IEEE Trans. Magnetics, vol. 47, 1732-1738, 2011.

[20] Ouadi, H., F. Giri, and L. Dugard. "Modeling saturated induction motors," In Proceedings of the IEEE International Conference on Control Applications, Vol. 1., 2004. 
[21] Ningping, Tang, Wu Hanguang, and Qiu Peiji. "A Saturation Model of Induction Machine by Space Vector," Electrical Machines and Systems, 2001. ICEMS 2001. Proceedings of the Fifth International Conference on. Vol. 1. IEEE, 2001.

[22] C.Pérez-Rojas. "Fitting Saturation and Hysteresis via Arctangent Functions," IEEE Power Eng. Rev. vol. 20, 55-57, 2000.

[23] A.Barili; A.Brambilla; G.Cottafava; E.Dallago. "A Simulation Model for the Saturable Reactor," IEEE Trans. Ind. Electron, vol.35, 301-306, 1988.

[24] D. C. Aliprantis; S. D. Sudhoff; B. T. Kuhn. "A Synchronous Machine Model with Saturation and Arbitrary Rotor Network Representation,” IEEE Trans. Energy Convers, vol. 20, 584-594, 2005.

[25] Saeedeh Hamidifar; Maryam Kazerooni; Narayan C. Kar. "A Novel Method to Represent the Saturation Characteristics of PMSM Using Levenberg-Marquardt Algorithm," In the proceedings of IEEE Conference on Vehicle Power and Propulsion Conference (VPPC), Chicago, IL, USA, 6-9 Sept. 2011.

[26] S. Pillutla, “A. Keyhani. Neural Network Based Saturation Model for Round Rotor Synchronous Generator," IEEE Trans. Energy Convers., vol. 14, no. 4, pp. 1019-1025, Dec. 1999.

[27] Kumar. G.S; Kishore.A. "A Generalized Dynamic Modeling and Analysis of Self-Excited Induction Generator using State-Space Approach with ANN-Model of Magnetizing Inductance," In the proceedings of IEEE International Conference on Industrial Technology, Mumbai, India, 15-17, Dec.2006.

[28] Elbashir, Omer Elfaki, Wang Zezhong, and Liu Qihui. "Analysis of DFIG Wind Turbine during Steady-State and Transient Operation." Indonesian Journal of Electrical Engineering and Computer Science 12, no. 6: 4148-4156, 2014.

[29] Song, Zhanfeng, Changliang Xia, and Tingna Shi. "Assessing Transient Response of DFIG Based Wind Turbines During Voltage Dips Regarding Main Flux Saturation And Rotor Deep-Bar Effect." Applied Energy 87, no. 10: 3283-3293, 2010.

[30] N. C. Kar; Saeedeh Hamidifar. "A Novel Approach to Saturation Characteristics Modeling and Its Impact on Synchronous Machine Transient Stability Analysis,” IEEE Trans. Energy Convers. vol 27, 139-150, 2012.

[31] J Yen; R Langari. "Fuzzy Logic Intelligence, Control and Information, Prentice Hall," 0135258170, 9780135258170, 1999.

[32] J.-S. R. Jang. “ANFIS: Adaptive-Network-Based Fuzzy Inference Systems,” IEEE Trans. Syst., Man, Cybern. vol. 23, 665-685, 1993.

[33] H. M. Jabr; N. C. Kar. "Neuro-Fuzzy Vector Control for Doubly-Fed Wind Driven Induction Generator," in Proceedings of the IEEE Electrical Power Conference, Montreal, Que., Canada ,25-26 Oct., 2007.

[34] Hamidifar, Saeedeh. "Regression Function Characterization of Synchronous Machine Magnetization and Its Impact on Machine Stability Analysis," PhD Thesis, University of Windsor, Canada, 2012.

\section{APPENDIX}

\begin{tabular}{ll}
\multicolumn{2}{c}{ DFIG Machine Ratings } \\
\hline \multicolumn{1}{c}{ Machine Ratings } \\
\hline Rated Power & $2.78 \mathrm{KVA}$ \\
Rated Voltage & $208 \mathrm{~V}$ \\
Rated Frequency & $60 \mathrm{~Hz}$ \\
Rated Power Factor & 0.72 \\
Rated Speed & $1,720 \mathrm{rpm}$ \\
\hline
\end{tabular}

